\title{
miR-10a is aberrantly overexpressed in Nucleophosmin 1 mutated acute myeloid leukaemia and its suppression induces cell death
}

\author{
Adam Bryant ${ }^{1}$, Catalina A Palma', Vivek Jayaswal ${ }^{2}$, Yee Wa Yang ${ }^{2}$, Mark Lutherborrow ${ }^{1,3}$ and David DF Ma, ${ }^{1,3^{*}}$
}

\begin{abstract}
Background: Acute myeloid leukaemia (AML) with nucleophosmin-1 (NPM1) mutation is a major subtype of AML. The NPM1 mutation induces a myeloproliferative disorder, but evidence indicates that other insults are necessary for the development of AML. We utilised microRNA microarrays and functional assays to determine if microRNA dysregulation could be involved in the pathogenesis of in NPM1 mutated (NPM1 ${ }^{\text {mut }}$ )-AML.

Results: We used a stringent locked nucleic acid (LNA) based microRNA microarray platform to profile bone marrow samples of patients with normal karyotype AML. A panel of five microRNAs dichotomised AML patients according to their NPM1 mutational status. miR-10a, let-7b and let-7c were significantly over-expressed, while miR130a and miR-335 were under-expressed in NPM1 ${ }^{\text {mut }}$-AML when compared to NPM1 $7^{\text {wildtype }}$-AML. Of these, miR-10a is the most differentially expressed in NPM1 ${ }^{\text {mut }}$-AML versus $N P M 1^{\text {wildtype }}$-AML $(>10$ fold higher as confirmed by qRT-PCR). To investigate the functions of miR-10a, the OCI-AML3 cell line was utilised, which is the only commercially available cell line bearing NPM1 mut. OCI-AML3 cells were firstly demonstrated to have a similarly high miR-10a expression to primary NPM ${ }^{\text {mut }}$-AML patient samples. Inhibition of miR-10a expression by miRCURY LNA Inhibitors (Exiqon) in these cells resulted in increased cell death as assessed by MTS, cell cycle and Annexin-V assays and reduced clonogenic capacity, indicative of an involvement in leukaemic cell survival. In silico filtering of bioinformatically predicted targets of miR-10a identified a number of potential mRNA targets with annotated functions in haematopoiesis, cell growth and apoptosis. Lucferase reporter assays confirmed a number of these putative tumorogenic genes that are miR-10a suppressible including KLF4 and RB1CC1. This provides a potential mechanism for the pathogenic role of miR-10a in NPM1 ${ }^{\text {mut }}$-AML.
\end{abstract}

Conclusions: This study provides, for the first time, in vitro evidence of a pro-survival role of miR-10a in NPM1 ${ }^{\text {mut }}$ $A M L$, that it may contribute to the pathogenesis of NPM1 ${ }^{m u t}-A M L$ and identifies putative tumorogenic targets.

Keywords: Acute myeloid leukaemia (AML), Nucleophosphmin1, microRNA, miR-10a, microarray, Cell death

\section{Background}

Acute myeloid leukaemia (AML) represents the convergent outcome a number of genetic abnormalities that have consequence in crucial cellular pathways of haematopoiesis. With an increasing knowledge of cellular processes and an accompanying improvement in our ability to interrogate these pathways, a spectrum of recurrent genetic abnormalities relevant to AML has become

\footnotetext{
* Correspondence: d.ma@amr.org.au

'Blood, Stem Cells and Cancer Research. St Vincent's Centre for Applied

Medical Research, St Vincent's Hospital, Sydney, NSW, Australia

Full list of author information is available at the end of the article
}

increasingly apparent. While most AML cases have at least one detectable genetic mutation potentially responsible for their pathogenesis, there remains a significant minority in which no abnormality is detectable [1].

MicroRNA-mediated post-transcriptional control of gene expression is a relatively newly discovered mechanism of cellular regulation that could account for some of the gaps in our knowledge of AML pathogenesis [2]. Through their repressive action on complementary sites in 3' untranslated regions (3'UTR) of target genes [2], these short 19-25 nucleotide RNA species are important in numerous processes including haematopoietic stem

\section{Biomed Central}

(C) 2012 Bryant et al; BioMed Central Ltd. This is an Open Access article distributed under the terms of the Creative Commons Attribution License (http://creativecommons.org/licenses/by/2.0), which permits unrestricted use, distribution, and reproduction in any medium, provided the original work is properly cited. 
cell maintenance [3] and progenitor self-renewal [4], myeloid differentiation [5-7], cell cycle and proliferation $[8,9]$, apoptosis $[10,11]$ and gene methylation [12]. All of these pathways are of potential relevance to AML pathogenesis if dysregulated.

NPM1-mutated $A M L$ (NPM1 $\left.1^{\text {mut }}-A M L\right)$ accounts for approximately $30 \%$ of cases of adult AML (and up to $60 \%$ of AML with normal karyotype) [13]. Recently $N P M 1^{m u t}$ activation has been found to initiate a myeloproliferative disorder after knock-in into mouse haematopoietic stem cells, however co-expression with a secondary mutation was proposed to be needed for overt AML development [14]. Global microRNA expression was assayed in a cohort of normal karyotype AML (NK-AML) using a stringent LNA-based microarray platform. We showed that among other differentially expressed microRNAs miR-10a, but not miR-10b, was significantly markedly over-expressed in $N P M 1^{\text {mut }}$-AML versus AML not bearing NPM1 gene insertions $\left(N P M 1^{W T}-A M L\right)$. It is also demonstrated that the only available NPM1 mutated cell line, OCI-AML3, exhibits high miR-10a expression. We have demonstrated that knockdown of over-expressed miR-10a in these cells resulted in reduced cellular survival and clonogenic growth. Using luciferase reporter analysis, we confirmed several miR-10a suppressible target genes located in key cellular pathways of significance to AML. Together, these findings suggest miR-10a may provide a pro-survival signal contributing to the pathogenesis of $N P M 1^{\mathrm{mut}}$ AML.

\section{Results}

microRNA profiling of AML samples by NPM1 mutational status

Analysis of microRNA expression of NK-AML samples demonstrated a clear pattern of clustered expression according to NPM1 mutational status, with three microRNAs over-expressed in NPM1 ${ }^{\text {mut }}$-AML (miR-10a, let$7 \mathrm{~b}$ and let-7c) and two microRNAs under-expressed (miR-130a and miR-335) (Figure 1A and 1B).

Furthermore, miR-10a was the most over-expressed microRNA with a FC of 19.6 as compared to normal bone marrow (Additional file 1: Table S1). miR-10a was 13.4 fold over-expressed in NPM1 ${ }^{\text {mut }}$-AML compared to $N P M 1^{W T}$-AML samples, indicative of the potential importance of miR-10a in NPM1 $1^{\text {mut }}$-AML (Figure 1B). In comparison for miR-10b (whose sequence only differs from miR-10a by a single base pair), the magnitude of the FC was only 1.4. Further to this, the expression of ratio of miR-10a to miR-10b in the NPM1 $1^{\text {mut }}$ samples was 53:1. This indicates that miR-10a and not miR-10b is the dominantly expressed gene in NPM1 ${ }^{\text {mut }}$-AML.

qRT-PCR was used to confirm that miR-10a expression is significantly higher in the NPM1 $1^{m u t}$-AML group
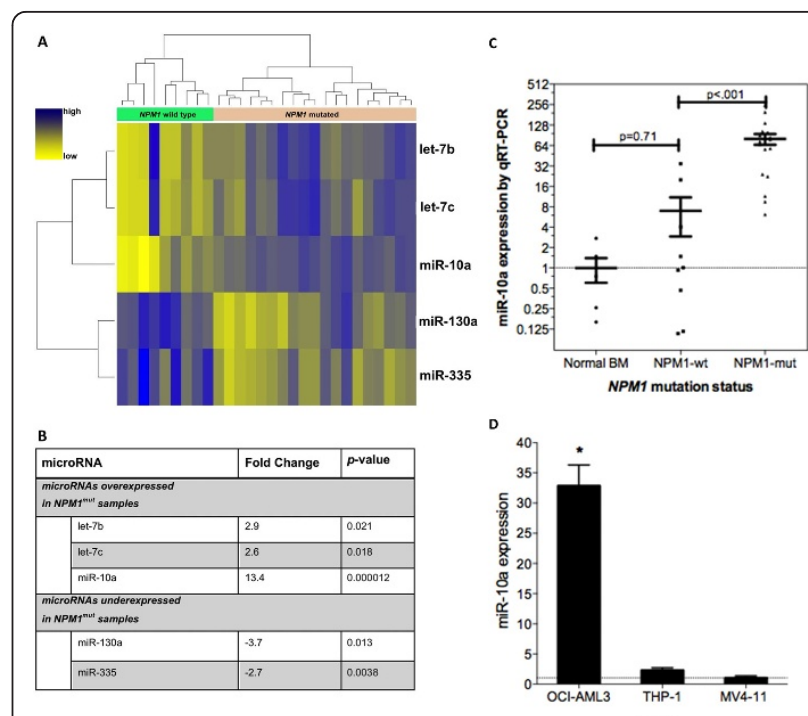

Cell Line

Figure 1 Unique microRNA signature of $N P M 1^{\text {mut }} A M L$ is characterised by miR-10a over-expression. A Hierarchical cluster analysis of $28 \mathrm{AML}$ samples according to NPM1 mutational status, with over-expression of miR-10a, let-7b, let-7c and under-expression of miR-130a and miR-335, with accompanying fold change B. C Validation of miR-10a expression by qRT-PCR in normal bone marrow, NPM1 ${ }^{\text {wt }}$-AML and NPM1 ${ }^{\text {mut }}$-AML respectively, with values presented normalised to the mean of the normal bone marrow samples. D miR-10a expression by qRT-PCR in selected malignant cell lines: MV4-11, OCI-AML3 (myelomonoblastic) and THP-1 (monoblastic). The expression values are depicted relative to that of MV4-11 cells, which had the lowest miR-10a expression. Error bars denote SEM. ${ }^{*} p<0.05$ by Unpaired Two-tailed T-test.

compared to both $N P M 1^{W T}$-AML and normal BM samples (mean FC values of 79.9, 7.0 and 1.0 respectively) (Figure 1C). Thus while there was some overlap of miR10a expression between NPM1 $1^{\text {mut }}$ and NPM1 $1^{W T}$-AML samples, high levels of miR-10a expression were very specific for $N P M 1^{m u t}$-AML. miR-10a expression was not significantly DE between normal bone marrow and $N P M 1^{W T}-A M L$.

\section{Inhibition of miR-10a expression by antisense LNA oligonucleotides}

miR-10a was expressed at higher levels in OCI-AML3 cells than other myelomonocytic leukeamic cell lines (Figure 1D). These results indicate that OCI-AML3 cells recapitulate the miR-10a expression of their parental primary leukaemic sample and may therefore serve as a useful model for study of miR-10a over-expression and its relationship with the NPM1 mutation.

Transfection of OCI-AML3 cells with anti-miR-10a LNA resulted in knockdown of miR-10a expression as assessed by qRT-PCR and by reporter assay (Additional file 2: Figure S1). As determined by MTS assay, inhibition of miR-10a resulted in significant reduction in cell 
count $(19 \%, p<0.01)$ at $48 \mathrm{~h}$ compared to treatment with a non-targeting LNA (Figure 2A).

miR-10a knockdown resulted in increased proportions of Annexin- $\mathrm{V}$ positive events compared to control treated cells by $34.9 \%$ and $39.3 \%$ at 24 and 48 h respectively, indicating increased cell death (Figure $2 \mathrm{C}, \mathrm{n}=4$ ). Furthermore, knockdown of miR-10a resulted in a $29.4 \%$ increase in the number of cells in the sub- $\mathrm{G}_{1}$ fraction of the cell cycle (Figure 2D, $n=4$ ) also indicating an increase in cell death. Caspase- 3 activation was not detected in the assays analysed in response to miR10a knockdown (data not shown), indicating that the increased cell death was not due to classical activation of apoptosis. Further flow cytometry analysis did not show a perturbation in cell cycle composition or cellular proliferation (PI and BrdU respectively, data not shown). miR-10a knockdown was not found to have an influence on the monocytic differentiation potential of OCIAML3 cells, with no significant difference in CD14, CD15 or CD11b expression after 48 or $96 \mathrm{~h}$ of induction culture with 1,25-dihydroxyvitaminD3 (Additional file 3: Figure S2).

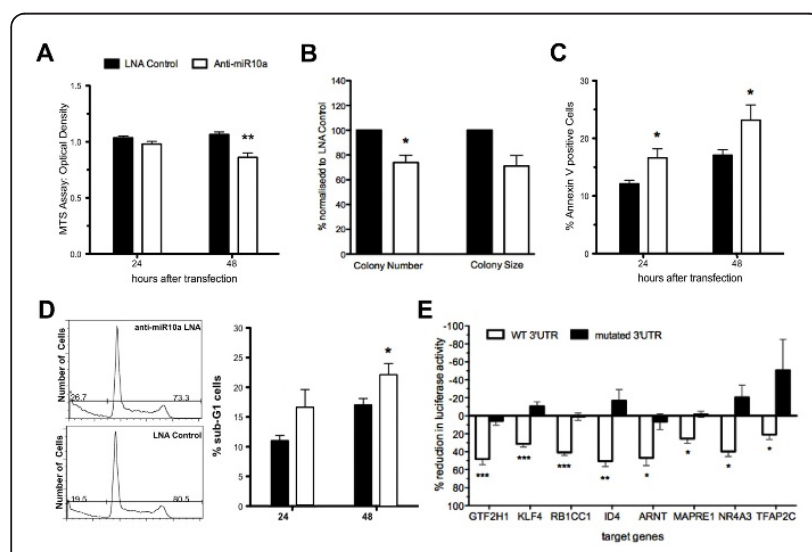

Figure 2 Functional effects of miR-10a. A. Transfection of $\mathrm{OCl}$ AML3 cells with anti-miR10a LNA resulted in 19\% reduction in cell count at $48 \mathrm{~h}$ as determined by MTS assay. B Assessment of clonogenic potential found a significant decrease in mean colony number (left), and a trend towards reduced Colony Size (right). Values are normalised to Scrambled LNA Control. C A significant increase in the number of Annexin- $V$ positive events at 24 and $48 \mathrm{~h}$. D Cell cycle analysis demonstrated an increase in the proportion of cells in the SubG1 fraction at 24 and 48 h post miR-10a knockdown. Black bars = Scrambled LNA Control, White bars = Anti-miR10a LNA transfected OCl-AML3 cells. E Confirmation of predicted miR-10a gene targets by luciferase reporter assay: ARNT, GTFH1, ID4, KLF4, MAPRE1, NR4A3, RB1CC1 and TFAP2C were confirmed to be miR-10a repressible by this assay. White bars $=$ miR-10a repression of $3^{\prime} U T R$ of the gene of interest, Black bars = miR10a repression of mutated miR-10a binding site on the 3'UTR of the gene of interest. All values were subject to normalisation to renilla luciferase activity of a nonspecific transfection control. Error bars denote SEM. For all experiments $n \geq 3$, statistical significance determined by Two-Tailed T-Test. ${ }^{*} p<0.05,{ }^{* *} p<0.01,{ }^{* * *} p<0.001$.
Clonogenic potential of OCI-AML3 cells (Figure 2B) demonstrated that knock-down in miR-10a levels resulted in a reduced clonogenic capacity, with significant reduction in colony number after 14 days $(26.1 \%, p$ $<0.05)$, with an associated trend towards smaller colony size. These in vitro studies suggest miR10a has a prosurvival role in the $N P M 1^{\text {mut }}$-AML cell line.

\section{Prediction and functional analysis of miR-10a targets}

To identify genes potentially responsible for these functional findings, we utilised the miRanda, PicTar and TargetScan algorithms to predict mRNA targets of miR10a. This search yielded 976, 133 and 143 mRNA targets respectively for a total 1071 unique targets. 44 genes were simultaneously predicted by all three algorythms (Table 1), and these will be referred to as stringently predicted targets.

A list of genes that are known to be or could be hypothesised to be dysregulated in AML was compiled, and interrogated back to the permissively identified set of potential miR-10a targets. Several resources were utilised to compile this catalogue (as indicated in Table 2). Advantage was also taken of published NPM1 $1^{\text {mut }}$-AML gene expression profiling data [15-17] by compiling a list of genes down-regulated in NPM1 $1^{\text {mut }}$-AML on the microarrays. Correlating these genes with the 1071 predicted miR-10a targets revealed potential miR-10a gene targets in each group as listed in Table 2. Of particular note, the Sanger Cancer Census genes ARNT, BCL6 and $N R 4 A 3$, as well at the G.O.C. myeloid-related gene NCOA6 (GO:0003099), each were also stringently predicted miR-10a targets of the 3 predictive algorithms. With respect to the genes down-regulated in NPM1 ${ }^{m u t}$ AML, CENTD1, ITM2A, RARA and SPARC each possess permissively identified miR-10a binding sites.

Table 1 miR-10a targets predicted by each of miRanda, PicTar and TargetScan.

\begin{tabular}{|c|c|c|c|}
\hline \multicolumn{4}{|c|}{$\begin{array}{l}\text { miR-10a gene targets predicted by miRanda, TargetScan and } \\
\text { PicTar }\end{array}$} \\
\hline ACTG1 & DOCK11 & MAPRE1 & SDC1 \\
\hline ANKRD12 & DVL3 & NARG1 & SFRS1 \\
\hline ARNT & ELAVL2 & NCOA6 & SLC25A1 \\
\hline ASXL1 & FHL3 & NCOR2 & SLC38A2 \\
\hline$\overline{\text { BCL6 }}$ & FXR2 & NR4A3 & SMAP1 \\
\hline BCL2L2 & GRM3 & NR5A2 & SON \\
\hline BTBD11 & GTF2H1 & PAFAH1B1 & SVOP \\
\hline$\overline{B T B D 14 B}$ & HNRPK & POPDC2 & TFAP2C \\
\hline CNNM4 & HOXD10 & PURB & USF2 \\
\hline$\overline{\text { CTDSPL }}$ & ID4 & RAP2A & WNK3 \\
\hline DAZAP1 & IL1RAPL1 & RB1CC1 & ZMYND11 \\
\hline
\end{tabular}

Of a total of unique 1071 mRNA targets predicted across the three algorithms, 44 were predicted to be targeted by miR-10a by all three 
Table 2 miR-10a targets in pathways of potential relevance to AML.

\begin{tabular}{|c|c|c|c|c|c|c|}
\hline \multicolumn{2}{|c|}{ Cancer Census Genes } & \multirow{2}{*}{$\begin{array}{l}\text { KEGG AML } \\
n=57\end{array}$} & \multirow{2}{*}{$\begin{array}{l}\text { KEGG apoptosis } \\
n=62\end{array}$} & \multirow{2}{*}{$\begin{array}{l}\text { KEGG cell cycle } \\
n=124\end{array}$} & \multirow{2}{*}{$\begin{array}{l}\text { G.O.C. - myeloid related } \\
n=80\end{array}$} & \multirow{2}{*}{$\begin{array}{l}N P M 1^{\text {mut }} \text {-AML gene array } \\
n=53\end{array}$} \\
\hline$n=366$ & & & & & & \\
\hline ARNT & MLLT6 & PIK3CA & BAX & CCNB3 & KLF4 & CENTD1 \\
\hline BCL6 & NF2 & RARA & BCL2L11 & CDK4 & NCOA6 & ITM2A \\
\hline CDK4 & NONO & & CASP9 & CDKN2A & PURB & RARA \\
\hline CREBBP & NR4A3 & & $\mathrm{FOXO3}$ & CREBBP & RASGRP4 & SPARC \\
\hline ERBB2 & PDE4DIP & & IRAK4 & ORC1L & & \\
\hline ERCC3 & PIK3CA & & & ORC2L & & \\
\hline FANCD2 & PTEN & & & ORDC5L & & \\
\hline FOXO3 & RARA & & & & & \\
\hline FUS & RECQL4 & & & & & \\
\hline HMGA2 & SSX2 & & & & & \\
\hline MLLT10 & WRN & & & & & \\
\hline
\end{tabular}

The genes listed in this table are those in each pathway that are also one of the 1071 permissively identified miR-10a targets. $n$ refers to the number of genes in each pathway interrogated for miR-10a targets. The genes linked to each of the heading in this table are listed in supplemental section. The final column refers to genes that were down regulated in three mRNA gene expression profiling studies of NPM1 ${ }^{\text {mut }}$-AML [15-17]. The genes denoted in bold are those that were also stringently identified by all 3 prediction programs. KEGG- Kyoto Encyclopaedia of Genes and Genomes. GOC.- Gene Ontology Consortium

Twelve genes were selected from the genes listed in Tables 1 and 2 for further analysis by reporter assay: ARNT, CTDSPL, ID4, GTF2H1, KLF4, MAPRE1, NFIX, NR4A3, NCOA6, NCOR2, RB1CC1, TFAP2C. Each of these genes has previously been demonstrated to be involved in malignant processes through their down-regulation. Reporter assay confirmed ARNT, GTFH1, ID4, KLF4, MAPRE1, NR4A3, RB1CC1 and TFAP2c to be miR-10a repressible genes, with further evidence of targetting specificity provided by site directed mutagenesis of the miR-10a binding site (Figure 2E).

\section{Discussion}

miR-10 family members are now implicated in the malignant transformation across a range of tissues through altered expression including breast cancer [18-21], colon and oesophageal cancer [22,23], glioblastoma [24-26], hepatocellular carcinoma [27], melanoma $[18,28]$, neurofibromatosis [29], pancreatic cancer [30] and urothelial carcinoma [31]. In murine models of breast carcinoma miR-10b has been demonstrated to have a crucial role in metastasis [19] with the pro-metastatic effect repressible by systemic antisense inhibition of miR-10b [21]. A similar role has also been demonstrated in oesophageal cell lines [22]. miR-10a may have a role in initial oncogenic transformation events evidenced by the finding that miR-10a enhances the transformation of NIH-3T3 cells by RAS-V12 [32]. Contrary to these findings miR-10a is actually down-regulated in chronic myeloid leukaemia (CML) CD34+ cells and over-expression of miR-10a retards the growth of KU812 cells (CML cell line) [33].

miR-10a first appeared in reference to AML when it was individually selected along with miR-10b for expression analysis in a cohort of AML cases [34], by virtue of its residence within HOX clusters known to be overexpressed in AML [35]. In a subsequent study, miR10a and miR-10b were found to be overexpressed (4.7 and 3.1 fold respectively) in NK-AML versus non NKAML [36,37]. Thus, miR-10 family expression appeared to be reflective of the HOX over-expression characteristic of NK-AML. The HOX expression profile itself appears more specific to NPM1 ${ }^{\text {mut }}$-AML which has the gene expression reminiscent of the haematopoietic stem cell [15].

Garzon et al., (2008) also compared microRNA expression between $N P M 1^{\text {mut }}$-AML versus $N P M 1^{W T}$ AML. They found that a microRNA signature, dominated by miR-10a, miR-10b and miR-100 over-expression in $N P M 1^{m u t}-A M L$, was able to accurately discriminate these AML subtypes. miR-10 family overexpression was also noted in two subsequent studies undertaking a similar comparison [38,39], but each utilising the alternative platform of a multiplexed TaqMan ${ }^{\circledR}$ MicroRNA Assay [40].

In each of the earlier publications miR-10a and miR$10 \mathrm{~b}$ were reported be co-overexpressed with a similar FC. However, it may be difficult to confidently discriminate miR-10a from miR-10b expression, since they differ at only a single nucleotide in the centre of the mature microRNA outside the seed site. While miR-10a and miR-10b share the same active 7 nucleotide seed site and therefore a vastly overlapping target profile, each is transcribed from distinct genomic locations and are likely to be controlled by their own cis-regulatory networks. The current study utilised a stringent LNA-based array which has a capacity to resolve miR-10a from miR-10b expression with cross-hybridisation of less than 
$10 \%$ for each probe. We found that while miR-10a was overexpressed in NPM1 $1^{\text {mut }}-A M L$ to a degree concordant with the earlier studies (13.4 fold), miR-10b was much more modestly DE (1.4 fold). Further to this, the expression ratio of miR-10a to miR-10b in the NPM1-mutated samples was $54: 1$. This suggests that miR-10a is the dominantly expressed family member in NPM1-AML cases, which verifies Garzon et al., finding [41] and is confirmed by a recent study by Ovchrenko et al. [42].

The normal physiological role of miR-10a is uncertain. miR-10a is deeply conserved both with respect to its sequence as well as its location within the HOXB cluster $[43,44]$. The finding that several HOX genes including HOXA1 [45], HOXA3 [46], HOXD4 [47] and HOXD10 [19] are repressible targets of miR-10 suggests that miR10 and HOX genes form an interconnected regulatory network with an important role in embryonic development. To date, minimal evidence exists to indicate that miR-10 has a physiological role in normal haematopoiesis, substantiated only by the observation that miR-10a is down-regulated as haematopoietic precursors mature towards certain differentiated progeny, such as megakaryocytes [48] or lymphocytes [49].

To further evaluate the potential role of miR-10a overexpression in NPM1 $1^{\text {mut }}$-AML, functional studies are required to address the possibility the over-expression may represent a passenger phenomenon consequent on a permissive chromatin configuration encompassing the HOXB locus. This is particularly important, since NPM1 $1^{\text {mut }}$-AML is known to possess a HOX up-regulated expression signature, although it is noted that miR-10a is not overexpressed in $M L L$-deregulated AMLs [38] which similarly upregulate HOX genes [50,51].

We conducted functional studies in the NPM1 $1^{\text {mut }}$ OCI-AML3 cell line. We have demonstrated in this study that knockdown of miR-10a overexpression in these cells lead to a decreased cell count after 48 hours in culture. Increased Annexin- $\mathrm{V}$ positive events but no change in cell cycling or proliferation was noted at 24 and 48 h. However, Caspase- 3 was not activated, which suggests that the reduced cell survival occurs by a mechanism other than classic apoptosis, such as necrosis, or via activation of Apoptosis-Inducible Factor leading to Caspase 3- independent apoptosis [52]. Interestingly, assessment of the clonogenic potential of OCI-AML3 cells by growth on semi-solid media found a decrease in the clonogenic potential of cells with miR10a knockdown, suggesting a possible role for miR-10a in self renewal pathways.

We acknowledge that this study is constrained by the current lack of NPM1 $1^{\text {mut }}$-AML cell lines, and future studies should determine the functional role of miR-10a by manipulating its expression levels in primary cells from
AML patients, both with $N P M 1^{w t}$ and $N P M 1^{\text {mut }}$, which has its own technical challenges. The interaction between miR-10a and NPM1 $1^{\text {mut }}$ needs to be defined. Evaluation of the leukaemogenic qualities of miR-10a, and its connection with the $N P M^{m u t}$, in murine models might address the unanswered issues raised by this study.

Prior to this study, only a short list of miR-10a repressible targets had been experimentally confirmed including Pbp1, RAN [32], USF2 [33] and the previously mentioned HOX genes. We wished to identify miR-10a gene targets which may explain the in vitro functional findings induced by suppression of miR-10a. Particular attention was paid to those genes that had previously been shown to contribute to AML (or other malignancies) by their down regulation. $R B 1 C C 1$ is a tumour suppressor and transcriptional promoter of key cell cycle regulator retinoblastoma-1 [53] that has been found to be inactivated in breast cancer by the intriguing means of truncational mutation [54]. Similarly, TFAP2C transcriptionally activates p 21 expression, retards breast cancer cell growth, and decreases clonogenic survival [55]. ID4 is a putative tumour suppressor gene that is down-regulated by hypermethylation in numerous cancers including ALL [56] and MDS [57]. KLF4 is not only a critical regulator of monocytic differentiation [58], but has been shown to be pathologically inactivated in medulloblastoma [59], and recently to interact with miR-10b in transition to oesophageal cancer [22]. NR4A3 has previously been demonstrated to be a critical tumor suppressor of myeloid leukemogenesis [60] and possesses two 3'UTR seed matches to miR-10a, which may increases capacity for translational repression [61]. ARNT was examined, since down-regulation of the $A H R / A R N T$ pathway by epigenetic means in acute lymphoblastic leukaemia (ALL) [62] may be extrapolatable to myeloid disease. GTF2H1 is a general transcription factor involved in nucleotide excision repair, contributing to the maintenance of genomic stability [63]. MAPRE1 is involved in microtubular physiology and maintenance of chromosomal stability [64], processes often disturbed in AML. We have demonstrated that these genes were shown to be the suppressible targets of miR-10a by report assays and warrant further investigation. The mechanism of miR-10a over-expression is unknown. It could be consequent upon copy number amplification at the $17 q 21.32$ locus where miR-10a resides, although this was not seen by high density SNP array (at 1 megabase resolution) in a cohort of AML patients which included 14 cases of NPM1-AML [65]. miR-10a expression is influenced by the methylation status of an upstream promoter [46], therefore analysis of the methylation status and the broader epigenetic state of the miR-10a locus in NPM1 $1^{\text {mut }}$-AML would be helpful. 


\section{Conclusions}

We have shown that miR-10a is markedly overexpressed in $N P M 1^{m u t}$-AML, and provided new evidence that miR-10a is the dominantly expressed miR-10 family member in this class of AML. NPM1 $1^{\text {mut }}$ OCIAML3 cell line shares high miR-10a expression with its primary AML derivative. Knockdown of miR-10a in these cells results in altered growth and cellular survival. In view of these findings as well as those in other malignancies, further evaluation of the role of miR-10a in $N P M 1^{\text {mut }}$ AML is warranted.

\section{Methods}

\section{Patient samples}

The diagnostic bone marrow samples of 28 NK-AML cases with pre-Ficoll marrow blast counts of at least $50 \%$ were obtained after informed consent from the tissue banks of our institute and the Australian Leukaemia and Lymphoma Group Tissue Bank (demographic data shown in Additional file 4: Table S2). Eight normal bone marrow samples were randomly obtained from our institute's tissue bank for comparison. To determine NPM1 mutational status, the insertional hotspot was RT-PCR amplified from complementary DNA using previously described primers [66] and directly sequenced on the 3100XL from ABI 3100XL Genetic Analyser using the reverse primer. 19/28 (68\%) samples harboured NPM1 ${ }^{\text {mut }}$.

\section{microRNA microarray and qRT-PCR}

RNA was extracted from post-ficoll bone marron mononuclear cells, and microRNA microarray (miRCURY LNA microRNA probe set, Cat \# 208010V8.1, Exiqon, Vedbaek, Denmark) performed as previously described in an overlapping cohort of patients [67]. The microarray was performed at the Adelaide Microarray Facility. In brief, $5 \mu \mathrm{g}$ of total fluorescent labelled RNA was analysed in duplicate by two-sample (dual colour) competitive hybridization with dye swap to control for labelling efficiency. Slides were scanned at $10 \mu \mathrm{m}$ resolution with a Genepix 4000B Scanner (Molecular Devices, Sunnyvale, $C A$ ). For the reference channel the total RNA from normal patient samples were pooled in equal quantities.

For the bioinformatic microarray analysis, data were processed as described [15] and [68]. We obtained the fold change (FC) of microRNAs differentially expressed (DE) between $N P M 1^{m u t}$ and $N P M 1^{w t}$-AML samples. For this analysis we tested the null hypothesis that the difference in log-2 fold change for NPM1 $1^{m u t}$ and $N P M 1^{w t}$ AML samples was 0 and the p-values were adjusted for multiple comparisons. Hierarchical cluster analysis was then performed using the probe sets identified to be significantly DE and a heat map was generated.
To confirm miR-10a expression in primary samples and comparison of expression in cell lines, $1 \mu \mathrm{g}$ of total RNA was used for cDNA synthesis reaction using the NCode microRNA first strand synthesis and qRT-PCR kit (Invitrogen, USA). Quantitative real time polymerase chain reaction (qRT-PCR) was performed using the Platinum Sybr Green Taq (Invitrogen, USA) and the Rotorgene RG-3000 thermocycler (Qiagen, Hilden, Germany). RNU6b was used as the housekeeping microRNA. The specific qRT-PCR primers were synthesised to order by Integrated DNA Technologies (USA) as follows: miR10a (5-taccctgtagatccgaatttgtg-3) and RNU6b (5cgcttcggcagcacatatac-3). For functional cell line work, microRNA expression was quantified by the TaqMan miRNA assay (Applied Biosystems) as per manufacturer's instructions, on the Rotorgene RG-3000 thermocycler. All qPCR reactions were performed in duplicate and RNU6b was also used as the housekeeping microRNA.

\section{miR-10a antisense repression and functional assays in OCI-AML3 cells}

The OCI-AML3 cell line is the only available AML cell line bearing the NPM1 gene mutation (type A TCTG duplication) and shares numerous phenotypic features with primary NPM1 $1^{\text {mut }}$-AML samples (14). OCI-AML3 cells purchased from the DSMZ cell-line bank (Braunschweig, Germany) were cultured in $\alpha$-MEM solution with $10 \%$ fetal bovine serum (GIBCO) once their NPM1 mutational status was confirmed. Cells were transfected with $50 \mathrm{nM}$ anti-miR10a miRCURY LNA ${ }^{\mathrm{TM}}$ microRNA knockdown probes or negative control (Exiqon, Denmark) using Lipofectamine 2000 and OptiMEM (both from Invitrogen, USA) in antibiotic-free media. Cells were maintained in a humidified incubator at $37^{\circ} \mathrm{C}$ in $5 \% \mathrm{CO} 2$. miR-10a knockdown was confirmed by TaqMan qRT-PCR (Applied Biosystems) (Additional file 3: Figure S2).

Cell growth and viability was analysed at 24 and $48 \mathrm{~h}$ using the Promega CellTiter Aqueous One Solution Cell Proliferation Assay (Promega) according to the manufacturer's instructions, using Multiskan plate reader (Thermo Labsystems). For this assay cells were plated in triplicate for each transfection condition and time point. The MTS absorbance reading at each time point was normalised to a non-transfected lipofectamine-only control.

Cell cycle analysis was performed by exposing cells to $1 \mathrm{~mL} 1 \% \mathrm{TX}-100,50 \mu \mathrm{L} 50 \mathrm{mg} / \mathrm{mL}$ propidium iodide (PI) and $50 \mu \mathrm{L}$ of $10 \mathrm{mg} / \mathrm{mL}$ RNAase $\mathrm{A}$ at $37^{\circ} \mathrm{C}$ for 30 min and analysed by the LSRII flow cytometer (BD biosciences).

Apoptotic fractions of LNA-transfected OCI-AML3 cells were analysed by Annexin V/PI staining using the 
Annexin V-FITC Apoptosis Detection Kit I (BD Pharminogen) according to the manufacturer's instructions. Caspase- 3 activation was measured using the platebased Caspase-Glo ${ }^{\circledR}$ 3/7 Assay (Promega). Intracellular activated caspase-3 was also directly measured by staining permeabilised cells (FACSperm, BD Biosciences) with PE Rabbit Anti-Active Caspase-3 (BD Pharmingen). Analysis was performed on FlowJo Software on at least 10,000 events acquired using a LSRII flow cytometer (BD Biosciences).

Clonogenicity of OCI-AML3 cells treated with antimiR10a LNA or negative control was assayed by seeding 400 OCI-AML3 cells in $1 \mathrm{~mL} \mathrm{1 \%}$ MethoCell MC (in RPMI with $10 \%$ FBS per $35 \mathrm{~mm}$ plate). Colony number and size were scored microscopically (colony defined as $>50$ cells) using standard criteria after 14 days at $37^{\circ} \mathrm{C}$ in $5 \% \mathrm{CO}_{2}$.

\section{miR-10a target prediction and validation}

miRanda (union of http://microRNA.org and miRBase), PicTar and TargetScan algorithms were utilised for the in silico prediction of miR-10a mRNA targets. The DAVID Functional Annotation Tool (http://david.abcc. ncifcrf.gov/summary.jsp) was used to classify the genes into ontologically-related terms and then examine for potentially enriched terms [69]. To identify genes of functional relevance in AML, several resources were utilised. To capture potential oncogenes or tumour suppressor genes, the Sanger Cancer Gene Census [70] was sourced. Next, the following Kyoto Encyclopaedia of Genes and Genomes (KEGG) Pathways [71] were considered: AML (hsa05221), apoptosis (hsa04210) and cell cycle (hsa04110). To capture genes related to myeloid differentiation, the following terms annotated by the Gene Ontology Consortium (GOC) [72] were considered: haematopoiesis (GO:0030097), myeloid cell differentiation (GO:0030099), myeloid leukocyte differentiation (GO:0002573) and several terms related to the regulation of these pathways (GO:0045637, GO:0045638, GO:0045639, GO:0002761, GO:0002762 and GO:0002763). Finally advantage was taken of published $N P M 1^{m u t}$-AML gene expression profiling data [15-17] by compiling a list of genes down-regulated in $N P M 1^{\text {mut }}$-AML on the microarrays.

Bioinformatically predicted miR-10a binding sites were analysed by luciferase reporter assay as described in detail previously [67]. To confirm the specificity of the 3'UTR binding site, at least 3 bases of the relevant seed region in the pMIR.3UTR constructs were mutated by site-directed mutagenesis (Stratagene) or by a PCRbased technique and the assay was repeated using the mutated construct.

\section{Additional material}

\begin{abstract}
Additional file 1: Table S1. List of significantly $(p<.05)$ differentially expressed probes on microarray comparison of NKAML samples versus normal bone marrow. Only those microRNAs with a FC of $\geq 2$ in either direction were included in this table. There were 26 overexpressed probes and 11 under expressed probes in NKAML versus normal BM. The microRNAs depicted in bold represent proprietary miRPlusTM probe whose sequences have subsequently been annotated on miRBase. Those probes denoted as miRPlusTM have not been further annotated by the release of miRBase release 15 .
\end{abstract}

Additional file 2: Figure S1. Confirmation of miR-10a knockdown by anti-10a LNA. A. miR-10a expression $24 \mathrm{~h}$ after transfection with Exiqon (LNA) anti-microRNA ASO was assayed by TaqMan microRNA qRT-PCR. RNU6b was used as the reference gene. MiR-10a expression was normalised to that of cells transfected with $100 \mathrm{nM}$ of the non-targeting control specific to each chemistry, with comparison made to untransfected cells The graph depicts the mean miR-10a relative expression of individual experiments for Ambion Anti-miRs $(n=4)$ and Exiqon LNAs ( $n=3$ ), +/-SEM (of fold change values). B. Hela cells were pre-treated with either pcDNA.10a (miR-10a overexpressing plasmid), 30 nM of Pre-miR-10a or were not pre-treated. After $6 \mathrm{~h}$, transfection media was removed and cells washed with PBS. Cells were then transfected with pMIR.HOXA1/pRLCMV and 50 nM of either anti-10a LNA or LNA Control A. After 24 h, Dual Luciferase Assay (Promega) was performed in triplicate. The whole experiment was repeated 5 times. The graph depicts the mean luciferase values for anti-10a LNA treated cells compared to the LNA Control A treated cells (+/-SEM), with the control values corrected to 100 . The statistical analysis consists of Student's t-test (paired). NS: not significant; ${ }^{*} 0.01<p<0.05 ;{ }^{* *} 0.001<p<0.01$.

Additional file 3: Figure S2. Monocytic differentiation of OCI-AML3 cells is not affected by miR-10a knockdown. 1,25-dihydroxyvitaminD3 (VitD3) was used to induce monocytic differentiation of OCl-AML3 cells over a $96 \mathrm{~h}$ period. A. Morphological analysis (Wright Stain) of cytospin samples of OCI-AML3 cells treated with VitD3 demonstrated no observable differences between SCRAM control transfected and antimiR10a LNA transfected groups. B. Phenotype analysis of CD14 C. CD15 and D. CD11b expression by flow cytometry did not detect a statistically significant difference between SCRAM control or anti-miR10a LNA groups at $48 \mathrm{~h}$ or $96 \mathrm{~h}$ post, regardless if cells were treated with VitD3 (+) or did not receive treatment $(-) . \mathrm{N}=3$.

Additional file 4: Table S2. Patient demographics and AML blast characteristics.

\section{Abbreviations}

AML: Acute myeloid leukaemia; NPM1: Nucleophosmin-1; NK: Normal karyotype; LNA: Locked nucleic acid.

\section{Acknowledgements}

This work was supported by grants from the Sydney Foundation for Medical Research, Arrow Bone Marrow Transplant Foundation, St Vincent's Clinic Foundation, St Vincent's Hospital Haematology Research Fund and the Australian National Health and Medical Research Council (AB scholarship).

\section{Author details}

${ }^{1}$ Blood, Stem Cells and Cancer Research. St Vincent's Centre for Applied Medical Research, St Vincent's Hospital, Sydney, NSW, Australia. ${ }^{2}$ School of Mathematics and Statistics, Sydney Bioinformatics Centre for Mathematical Biology, University of Sydney, Sydney, NSW, Australia. ${ }^{3}$ St Vincent's Clinical School, Faculty of Medicine, University of New South Wales, Sydney, NSW, Australia.

\section{Authors' contributions}

AB carried out qRT-PCR, apoptosis, cell cycle and cell growth assays, microRNA target prediction and validation by luciferace assay, and wrote the 
manuscript. CAP carried out the clonogenic, BrdU, differentiation assays and contributed to the apoptosis assays and wrote the manuscript. WY performed the bioinformatic microarray analysis. YWY contributed to statistical analysis. ML carried out the microarrays, participated in the design of the study and wrote the manuscript. DM conceived of the study, participated in its design, supervised the experiments and helped to write the manuscript. All authors read and approved the final manuscript.

\section{Competing interests}

The authors declare that they have no competing interests.

Received: 22 November 2011 Accepted: 20 February 2012

Published: 20 February 2012

\section{References}

1. Dohner H, Estey EH, Amadori S, Appelbaum FR, Buchner T, Burnett AK, Dombret H, Fenaux P, Grimwade D, Larson RA, et al: Diagnosis and management of acute myeloid leukemia in adults: recommendations from an international expert panel, on behalf of the European LeukemiaNet. Blood 2010, 115:453-474.

2. Palma CA, Tonna EJ, Ma DF, Lutherborrow M: MicroRNA control of myelopoiesis and the differentiation block in Acute Myeloid Leukaemia. J Cell Mol Med 2012, [Epub ahead of print].

3. Dickstein J, Senyuk V, Premanand K, Laricchia-Robbio L, Xu P, Cattaneo F, Fazzina R, Nucifora G: Methylation and silencing of miRNA-124 by EVI1 and self-renewal exhaustion of hematopoietic stem cells in murine myelodysplastic syndrome. Proc Natl Acad Sci USA 2010, 107:9783-9788.

4. Guo S, Lu J, Schlanger R, Zhang H, Wang JY, Fox MC, Purton LE, Fleming $\mathrm{HH}$, Cobb B, Merkenschlager M, et al: MicroRNA miR-125a controls hematopoietic stem cell number. Proc Natl Acad Sci USA 2010, 107:14229-14234.

5. Fazi F, Rosa A, Fatica A, Gelmetti V, De Marchis ML, Nervi C, Bozzoni I: A minicircuitry comprised of microRNA-223 and transcription factors NFI-A and C/EBPalpha regulates human granulopoiesis. Cell 2005, 123:819-831.

6. Fukao T, Fukuda Y, Kiga K, Sharif J, Hino K, Enomoto Y, Kawamura A, Nakamura K, Takeuchi T, Tanabe M: An evolutionarily conserved mechanism for microRNA-223 expression revealed by microRNA gene profiling. Cell 2007, 129:617-631.

7. Johnnidis JB, Harris MH, Wheeler RT, Stehling-Sun S, Lam MH, Kirak O, Brummelkamp TR, Fleming MD, Camargo FD: Regulation of progenitor cell proliferation and granulocyte function by microRNA-223. Nature 2008, 451:1125-1129.

8. Pulikkan JA, Dengler V, Peramangalam PS, Peer Zada AA, Muller-Tidow C, Bohlander SK, Tenen DG, Behre G: Cell-cycle regulator E2F1 and microRNA-223 comprise an autoregulatory negative feedback loop in acute myeloid leukemia. Blood 2010, 115:1768-1778.

9. Klein U, Lia M, Crespo M, Siegel R, Shen Q, Mo T, Ambesi-Impiombato A, Califano A, Migliazza A, Bhagat G, Dalla-Favera R: The DLEU2/miR-15a/16-1 cluster controls $B$ cell proliferation and its deletion leads to chronic lymphocytic leukemia. Cancer Cell 2010, 17:28-40.

10. Cimmino A, Calin GA, Fabbri M, lorio MV, Ferracin M, Shimizu M, Wojcik SE, Aqeilan Rl, Zupo S, Dono M, et al: miR-15 and miR-16 induce apoptosis by targeting BCL2. Proc Natl Acad Sci USA 2005, 102:13944-13949.

11. He L, He X, Lim LP, de Stanchina E, Xuan Z, Liang Y, Xue W, Zender L, Magnus J, Ridzon D, et al: A microRNA component of the p53 tumour suppressor network. Nature 2007, 447:1130-1134.

12. Garzon R, Liu S, Fabbri M, Liu Z, Heaphy CE, Callegari E, Schwind S, Pang J, Yu J, Muthusamy N, et al: MicroRNA-29b induces global DNA hypomethylation and tumor suppressor gene reexpression in acute myeloid leukemia by targeting directly DNMT3A and 3B and indirectly DNMT1. Blood 2009, 113:6411-6418.

13. Falini B, Mecucci $C$, Tiacci $E$, Alcalay M, Rosati R, Pasqualucci L, La Starza R, Diverio D, Colombo E, Santucci A, et al: Cytoplasmic nucleophosmin in acute myelogenous leukemia with a normal karyotype. $N$ Engl J Med 2005, 352:254-266

14. Vassiliou GS, Cooper JL, Rad R, Li J, Rice S, Uren A, Rad L, Ellis P, Andrews R, Banerjee $\mathrm{R}$, et al: Mutant nucleophosmin and cooperating pathways drive leukemia initiation and progression in mice. Nat Genet 2011, 43:470-475.

15. Alcalay M, Tiacci E, Bergomas R, Bigerna B, Venturini E, Minardi SP, Meani N, Diverio D, Bernard L, Tizzoni L, et al: Acute myeloid leukemia bearing cytoplasmic nucleophosmin (NPMc+ AML) shows a distinct gene expression profile characterized by up-regulation of genes involved in stem-cell maintenance. Blood 2005, 106:899-902.

16. Mullighan CG, Kennedy A, Zhou X, Radtke I, Phillips LA, Shurtleff SA, Downing JR: Pediatric acute myeloid leukemia with NPM1 mutations is characterized by a gene expression profile with dysregulated HOX gene expression distinct from MLL-rearranged leukemias. Leukemia 2007, 21:2000-2009.

17. Verhaak RG, Goudswaard CS, van Putten W, Bijl MA, Sanders MA, Hugens W, Uitterlinden AG, Erpelinck CA, Delwel R, Lowenberg B, Valk PJ: Mutations in nucleophosmin (NPM1) in acute myeloid leukemia (AML): association with other gene abnormalities and previously established gene expression signatures and their favorable prognostic significance. Blood 2005, 106:3747-3754.

18. Zhang L, Huang J, Yang N, Greshock J, Megraw MS, Giannakakis A, Liang S, Naylor TL, Barchetti A, Ward MR, et al: microRNAs exhibit high frequency genomic alterations in human cancer. Proc Natl Acad Sci USA 2006, 103:9136-9141.

19. Ma L, Teruya-Feldstein J, Weinberg RA: Tumour invasion and metastasis initiated by microRNA-10b in breast cancer. Nature 2007, 449:682-688.

20. Moriarty $\mathrm{CH}$, Pursell B, Mercurio AM: miR-10b targets Tiam1: implications for Rac activation and carcinoma migration. J Biol Chem 2010 285:20541-20546.

21. Ma L, Reinhardt F, Pan E, Soutschek J, Bhat B, Marcusson EG, TeruyaFeldstein J, Bell GW, Weinberg RA: Therapeutic silencing of miR-10b inhibits metastasis in a mouse mammary tumor model. Nat Biotechnol 2010, 28:341-347.

22. Tian Y, Luo A, Cai Y, Su Q, Ding F, Chen H, Liu Z: MicroRNA-10b promotes migration and invasion through KLF4 in human esophageal cancer cell lines. J Biol Chem 2010, 285:7986-7994.

23. Volinia S, Calin GA, Liu CG, Ambs S, Cimmino A, Petrocca F, Visone R, lorio $\mathrm{M}$, Roldo $\mathrm{C}$, Ferracin $\mathrm{M}$, et al: A microRNA expression signature of human solid tumors defines cancer gene targets. Proc Natl Acad Sci USA 2006, 103:2257-2261

24. Gaur A, Jewell DA, Liang Y, Ridzon D, Moore JH, Chen C, Ambros VR, Israel MA: Characterization of microRNA expression levels and their biological correlates in human cancer cell lines. Cancer Res 2007, 67:2456-2468.

25. Silber J, Lim DA, Petritsch C, Persson Al, Maunakea AK, Yu M, Vandenberg SR, Ginzinger DG, James CD, Costello JF, et al: miR-124 and miR-137 inhibit proliferation of glioblastoma multiforme cells and induce differentiation of brain tumor stem cells. BMC Med 2008, 6:14.

26. Ciafre SA, Galardi S, Mangiola A, Ferracin M, Liu CG, Sabatino G, Negrini M, Maira G, Croce CM, Farace MG: Extensive modulation of a set of microRNAs in primary glioblastoma. Biochem Biophys Res Commun 2005, 334:1351-1358.

27. Varnholt H, Drebber U, Schulze F, Wedemeyer I, Schirmacher P, Dienes HP, Odenthal M: MicroRNA gene expression profile of hepatitis $C$ virusassociated hepatocellular carcinoma. Hepatology 2008, 47:1223-1232.

28. Jukic DM, Rao UN, Kelly L, Skaf JS, Drogowski LM, Kirkwood JM, Panelli MC: Microrna profiling analysis of differences between the melanoma of young adults and older adults. J Trans/ Med 2010, 8:27.

29. Chai G, Liu N, Ma J, Li H, Oblinger JL, Prahalad AK, Gong M, Chang LS, Wallace $M$, Muir D, et al: MicroRNA-10b regulates tumorigenesis in neurofibromatosis type 1. Cancer Sci 2010, 101:1997-2004.

30. Bloomston M, Frankel WL, Petrocca F, Volinia S, Alder H, Hagan JP, Liu CG, Bhatt D, Taccioli C, Croce CM: MicroRNA expression patterns to differentiate pancreatic adenocarcinoma from normal pancreas and chronic pancreatitis. JAMA 2007, 297:1901-1908.

31. Veerla S, Lindgren D, Kvist A, Frigyesi A, Staaf J, Persson H, Liedberg F, Chebil G, Gudjonsson S, Borg A, et al: MiRNA expression in urothelial carcinomas: important roles of miR-10a, miR-222, miR-125b, miR-7 and miR-452 for tumor stage and metastasis, and frequent homozygous losses of miR-31. Int J Cancer 2009, 124:2236-2242.

32. Orom UA, Nielsen FC, Lund AH: MicroRNA-10a binds the $5^{\prime} U T R$ of ribosomal protein mRNAs and enhances their translation. Mol Cell 2008, 30:460-471.

33. Agirre $X$, Jimenez-Velasco A, San Jose-Eneriz E, Garate L, Bandres E, Cordeu L, Aparicio O, Saez B, Navarro G, Vilas-Zornoza A, et al: Downregulation of hsa-miR-10a in chronic myeloid leukemia CD34+ cells increases USF2-mediated cell growth. Mol Cancer Res 2008, 6:1830-1840. 
34. Debernardi S, Skoulakis S, Molloy G, Chaplin T, Dixon-Mclver A, Young BD: MicroRNA miR-181a correlates with morphological sub-class of acute myeloid leukaemia and the expression of its target genes in global genome-wide analysis. Leukemia 2007, 21:912-916.

35. Debernardi S, Lillington DM, Chaplin T, Tomlinson S, Amess J, Rohatiner A, Lister TA, Young BD: Genome-wide analysis of acute myeloid leukemia with normal karyotype reveals a unique pattern of homeobox gene expression distinct from those with translocation-mediated fusion events. Genes Chromosomes Cancer 2003, 37:149-158.

36. Garzon R, Volinia S, Liu CG, Fernandez-Cymering C, Palumbo T, Pichiorri F, Fabbri M, Coombes $\mathrm{K}$, Alder $\mathrm{H}$, Nakamura T, et al: MicroRNA signatures associated with cytogenetics and prognosis in acute myeloid leukemia. Blood 2008, 111:3183-3189.

37. Dixon-Mclver A, East P, Mein CA, Cazier JB, Molloy G, Chaplin T, Andrew Lister T, Young BD, Debernardi S: Distinctive patterns of microRNA expression associated with karyotype in acute myeloid leukaemia. PLOS One 2008, 3:e2141.

38. Jongen-Lavrencic M, Sun SM, Dijkstra MK, Valk PJ, Lowenberg B: MicroRNA expression profiling in relation to the genetic heterogeneity of acute myeloid leukemia. Blood 2008, 111:5078-5085.

39. Cammarata G, Augugliaro L, Salemi D, Agueli C, La Rosa M, Dagnino L, Civiletto G, Messana F, Marfia A, Bica MG, et al: Differential expression of specific microRNA and their targets in acute myeloid leukemia. Am J Hematol 2010, 85:331-339.

40. Chen C, Ridzon DA, Broomer AJ, Zhou Z, Lee DH, Nguyen JT, Barbisin M, $\mathrm{Xu} \mathrm{NL}$, Mahuvakar VR, Andersen MR, et al: Real-time quantification of microRNAs by stem-loop RT-PCR. Nucleic Acids Res 2005, 33:e179.

41. Garzon R, Garofalo M, Martelli MP, Briesewitz R, Wang L, FernandezCymering C, Volinia S, Liu CG, Schnittger S, Haferlach T, et al: Distinctive microRNA signature of acute myeloid leukemia bearing cytoplasmic mutated nucleophosmin. Proc Natl Acad Sci USA 2008, 105:3945-3950.

42. Ovcharenko D, Stolzel F, Poitz D, Fierro F, Schaich M, Neubauer A, Kelnar K, Davison T, Muller-Tidow C, Thiede C, et al: miR-10a overexpression is associated with NPM1 mutations and MDM4 downregulation in intermediate-risk acute myeloid leukemia. Exp Hematol 2011, 39(10301042):e1037.

43. Lagos-Quintana M, Rauhut R, Meyer J, Borkhardt A, Tuschl T: New microRNAs from mouse and human. RNA 2003, 9:175-179.

44. Mansfield JH, Harfe BD, Nissen R, Obenauer J, Srineel J, Chaudhuri A, Farzan-Kashani R, Zuker M, Pasquinelli AE, Ruvkun G, et al: MicroRNAresponsive 'sensor' transgenes uncover Hox-like and other developmentally regulated patterns of vertebrate microRNA expression. Nat Genet 2004, 36:1079-1083.

45. Garzon R, Croce CM: MicroRNAs in normal and malignant hematopoiesis. Curr Opin Hematol 2008, 15:352-358.

46. Han L, Witmer PD, Casey E, Valle D, Sukumar S: DNA methylation regulates MicroRNA expression. Cancer Biol Ther 2007, 6:1284-1288.

47. Tan Y, Zhang B, Wu T, Skogerbo G, Zhu X, Guo X, He S, Chen R: Transcriptional inhibiton of Hoxd4 expression by miRNA-10a in human breast cancer cells. BMC Mol Biol 2009, 10:12.

48. Garzon R, Pichiorri F, Palumbo T, Iuliano R, Cimmino A, Aqeilan R, Volinia S, Bhatt $D$, Alder $H$, Marcucci $G$, et al: MicroRNA fingerprints during human megakaryocytopoiesis. Proc Natl Acad Sci USA 2006, 103:5078-5083.

49. Petriv OI, Kuchenbauer F, Delaney AD, Lecault V, White A, Kent D, Marmolejo L, Heuser M, Berg T, Copley M, et al: Comprehensive microRNA expression profiling of the hematopoietic hierarchy. Proc Natl Acad Sci 2010, 107:15443-15448.

50. Milne TA, Briggs SD, Brock HW, Martin ME, Gibbs D, Allis CD, Hess JL: MLL targets SET domain methyltransferase activity to Hox gene promoters. Mol Cell 2002, 10:1107-1117.

51. Zeisig BB, Milne T, Garcia-Cuellar MP, Schreiner S, Martin ME, Fuchs U, Borkhardt A, Chanda SK, Walker J, Soden R, et al: Hoxa9 and Meis1 are key targets for MLL-ENL-mediated cellular immortalization. Mol Cell Biol 2004, 24:617-628.

52. Cregan SP, Dawson VL, Slack RS: Role of AIF in caspase-dependent and caspase-independent cell death. Oncogene 2004, 23:2785-2796.

53. Ikebuchi K, Chano T, Ochi Y, Tameno H, Shimada T, Hisa Y, Okabe H: RB1CC1 activates the promoter and expression of RB1 in human cancer. Int J Cancer 2009, 125:861-867.
54. Chano T, Kontani K, Teramoto K, Okabe H, Ikegawa S: Truncating mutations of RB1CC1 in human breast cancer. Nat Genet 2002, 31:285-288.

55. Li H, Goswami PC, Domann FE: AP-2gamma induces p21 expression, arrests cell cycle, and inhibits the tumor growth of human carcinoma cells. Neoplasia 2006, 8:568-577.

56. Yu L, Liu C, Vandeusen J, Becknell B, Dai Z, Wu YZ, Raval A, Liu TH, Ding W, Mao $C$, et al: Global assessment of promoter methylation in a mouse model of cancer identifies ID4 as a putative tumor-suppressor gene in human leukemia. Nat Genet 2005, 37:265-274

57. Wang $H$, Wang $X Q$, Xu XP, Lin GW: ID4 methylation predicts high risk of leukemic transformation in patients with myelodysplastic syndrome. Leuk Res 2010, 34:598-604.

58. Feinberg MW, Wara AK, Cao Z, Lebedeva MA, Rosenbauer F, Iwasaki H, Hirai H, Katz JP, Haspel RL, Gray S, et al: The Kruppel-like factor KLF4 is a critical regulator of monocyte differentiation. EMBO J 2007, 26:4138-4148.

59. Nakahara Y, Northcott PA, Li M, Kongkham PN, Smith C, Yan H, Croul S, Ra YS, Eberhart C, Huang A, et al: Genetic and epigenetic inactivation of Kruppel-like factor 4 in medulloblastoma. Neoplasia 2010, 12:20-27.

60. Mullican SE, Zhang S, Konopleva M, Ruvolo V, Andreeff M, Milbrandt J, Conneely OM: Abrogation of nuclear receptors Nr4a3 and Nr4a1 leads to development of acute myeloid leukemia. Nat Med 2007, 13:730-735.

61. Doench JG, Petersen CP, Sharp PA: siRNAs can function as miRNAs. Genes Dev 2003, 17:438-442.

62. Taniguchi H, Fernandez AF, Setien F, Ropero S, Ballestar E, Villanueva A, Yamamoto $H$, Imai K, Shinomura Y, Esteller M: Epigenetic inactivation of the circadian clock gene BMAL1 in hematologic malignancies. Cancer Res 2009, 69:8447-8454.

63. Lee GY, Jang JS, Lee SY, Jeon HS, Kim KM, Choi JE, Park JM, Chae MH, Lee WK, Kam S, et al: XPC polymorphisms and lung cancer risk. Int $J$ Cancer 2005, 115:807-813.

64. Tirnauer JS, Bierer BE: EB1 proteins regulate microtubule dynamics, cell polarity, and chromosome stability. J Cell Biol 2000, 149:761-766.

65. Bullinger L, Kronke J, Schon C, Radtke I, Urlbauer K, Botzenhardt U, Gaidzik V, Cario A, Senger C, Schlenk RF, et al: Identification of acquired copy number alterations and uniparental disomies in cytogenetically normal acute myeloid leukemia using high-resolution single-nucleotide polymorphism analysis. Leukemia 2010, 24:438-449.

66. Quentmeier H, Martelli MP, Dirks WG, Bolli N, Liso A, Macleod RA, Nicoletti I, Mannucci R, Pucciarini A, Bigerna B, et al: Cell line OCI/AML3 bears exon12 NPM gene mutation-A and cytoplasmic expression of nucleophosmin. Leukemia 2005, 19:1760-1767.

67. Lutherborrow M, Bryant A, Jayaswal V, Agapiou D, Palma C, Yang YH, Ma DD: Expression profiling of cytogenetically normal acute myeloid leukemia identifies microRNAs that target genes involved in monocytic differentiation. Am J Hematol 2011, 86:2-11.

68. Smyth G: Limma Linear Models for microarray data. In Bioinformatics and Computational Biology Solutions using $R$ and Bioconductor. Edited by: Gentleman R, Carey V, Dudoit S, Irizarry R, Huber W. New York: Springer; 2005:

69. Huang DW, Sherman BT, Lempicki RA: Systematic and integrative analysis of large gene lists using DAVID bioinformatics resources. Nat Protoc 2009, 4:44-57.

70. Futreal PA, Coin L, Marshall M, Down T, Hubbard T, Wooster R, Rahman N, Stratton MR: A census of human cancer genes. Nat Rev Cancer 2004, 4:177-183

71. Kanehisa M, Goto S: KEGG: kyoto encyclopedia of genes and genomes. Nucleic Acids Res 2000, 28:27-30.

72. Ashburner M, Ball CA, Blake JA, Botstein D, Butler H, Cherry JM, Davis AP, Dolinski K, Dwight SS, Eppig JT, et al: Gene ontology: tool for the unification of biology. The gene ontology consortium. Nat Genet 2000, 25:25-29.

doi:10.1186/1476-4598-11-8

Cite this article as: Bryant et al:: miR-10a is aberrantly overexpressed in Nucleophosmin 1 mutated acute myeloid leukaemia and its suppression induces cell death. Molecular Cancer 2012 11:8. 